\title{
Analisis Kepuasan dan Loyalitas Konsumen Midori Japanese Restaurant Cabang \\ K.H. Wahid Hasyim Jakarta Pusat
}

\author{
Tintin Sarianti dan Rr.Prita.E Putriana \\ Departemen Agribisnis - Fakultas Ekonomi dan Manajemen IPB
}

ABSTRACT

Citizen consumption for the times towards food is more increase. This matter will be influenced by the increasing need of citizen on nutrition and nutrient. This phenomenon is followed by the existence of many restaurants as business caterers. Jakarta is one of the cities in Indonesia with a variety of diversity, including in terms of food. There are various kinds of foods sold in restaurants in Jakarta, both from within and outside the country. One of them is a unique Japanese food. Currently, there are more and more Japanese food restaurants in Jakarta. One of the restaurants that still survive until this day is Midori Japanese Restaurant. In maintaining its business, Midori Japanese Restaurant needed to explore its consumer characteristics, consumer satisfaction, and consumer loyalty. The restaurant can implement marketing strategies to maintain its business. This research was commenced from March to May 2010 and conducted at Midori Japanese Restaurant branch K.H. Wahid Hasyim Central Jakarta. This research used descriptive analysis for consumer characteristics, Customer Satisfaction Index (CSI), Importance Performance Analysis (IPA) to know the attributes improvements, and loyalty pyramid to determine the level of consumer loyalty. This research also provided recommendations that can be done as marketing strategy.

Keywords: Japanese food, consumer characteristics, consumer satisfaction, consumer loyalty, descriptive analysis, Customer Satisfaction Index (CSI), Importance Performance Analysis (IPA), loyalty pyramid.

\section{Latar Belakang}

\section{PENDAHULUAN}

Jakarta adalah salah satu kota yang terus mengalami peningkatan dari segi jumlah, proporsi, dan kepadatan penduduknya. Hal ini didukung karena Jakarta merupakan ibukota negara Indonesia yang terletak di provinsi DKI Jakarta. Terdapat peningkatan jumlah dan proporsi penduduk DKI Jakarta pada tahun 1990 sebesar 8.259 .600 jiwa menjadi 9.057.993 jiwa pada tahun 2007. Peningkatan jumlah, proporsi, dan pertumbuhan penduduk di DKI Jakarta tersebut akan mengakibatkan peningkatan jumlah konsumsi (terutama untuk makanan) penduduk DKI Jakarta.

Makanan dan minuman menempati urutan pertama untuk konsumsi makanan bagi penduduk DKI Jakarta pada tahun 2007 yaitu sebesar 92.634 konsumsi dan meningkat di tahun 2008 menjadi 120.751 konsumsi. Dengan semakin meningkatnya jumlah konsumsi makanan, beberapa pihak memanfaatkan kesempatan ini untuk mendirikan usaha penyedia makanan, salah satunya dalam bentuk restoran. Jumlah restoran di DKI Jakarta pada tahun 2008 pun meningkat sebesar 38,39 persen (Badan Pusat Statistik, 2008).

Dalam menjalankan usaha restoran, perlu memperhatikan kepuasan konsumen terhadap produk yang ditawarkan. Kepuasan konsumen perlu ditingkatkan karena tingginya tingkat persaingan restoran yang ada di DKI Jakarta, dimana setiap tahunnya pertumbuhan rata-rata untuk jenis usaha restoran di DKI jakarta mencapai 6,84\% (Dinas Pariwisata dan Kebudayaan DKI Jakarta, 2010). Besarnya pertumbuhan rata-rata restoran di DKI Jakarta yang memiliki berbagai ragam masakan dari masakan tradisional sampai masakan internasional.

Salah satu jenis masakan internasional yang diminati oleh penduduk DKI Jakarta adalah masakan Jepang. Massakan Jepang merupakan salah satu jenis masakan yang 
memiliki keunikan tersendiri baik dalam proses pembuatannya maupun penyajiannya. Salah satu restoran di DKI Jakarta yang menyajikan masakan Jepang yaitu Midori Japanese Restaurant. Restoran ini merupakan salah satu restoran Jepang yang telah berdiri sejak lama dan tetap eksis serta diminati oleh masyarakat DKI Jakarta sampai saat ini.

Midori Japanese Restaurant berdiri pada 30 Juni 1994. Restoran ini merupakan restoran Jepang asli, dalam arti, mulai dari menu, cara memasak, material/bahan-bahan, bumbu hingga peralatan makan, berasal asli dari Jepang. Tidak hanya detil hidangan yang disajikan, suasana yang tenang dan nyaman pada restoran juga sangat mendukung. Saat ini, Midori Japanese Restaurant telah memiliki sembilan cabang, yaitu enam cabang di DKI Jakarta, satu cabang di Anyer, satu cabang di Bandung dan satu cabang di Bogor. Dari enam cabang yang berada di DKI Jakarta terdapat cabang K.H. Wahid Hasyim yang merupakan cabang terbaru di wilayah DKI Jakarta.

Berdasarkan hasil wawancara dengan manajer Midori Japanese Restaurant, ratarata jumlah pengunjung Midori Japanese Restaurant cabang K.H. Wahid Hasyim setiap bulannya adalah sekitar 1.500 orang. Jumlah ini dapat dikatakan jumlah yang rendah dibandingkan dengan Midori Japanese Restaurant di cabang lainnya, seperti Midori Japanese Restaurant cabang Pondok Indah yang rata-rata jumlah pengunjungnya 2.5003.000 per bulan. Perbedaan rata-rata jumlah pengunjung ini menggambarkan bahwa kemungkinan terdapat perbedaan karakteritik konsumen dari Midori Japanese Restaurant antar cabang. Jumlah pengunjung Midori Japanese Restaurant cabang K.H. Wahid Hasyim yang lebih rendah dibandingkan cabang lainnya akan mendorong pihak restoran untuk meningkatkan kepuasan dan loyalitas konsumen agar jumlah pengunjung restoran dapat meningkat setiap bulannya. Selain itu, persaingan yang tinggi juga terjadi pada usaha restoran Jepang, khususnya di Jakarta Pusat. Pada wilayah sekitar K.H. Wahid Hasyim, M. H. Thamrin, Cikini, dan Menteng Jakarta Pusat sendiri terdapat 18 restoran lain dengan menu masakan yang sama yaitu restoran dengan menu masakan Jepang seperti Aji Hei, Sakae Sushi, ebuya, edogin, dan Hoka Hoka Bento. Oleh karena itu penting bagi pihak retoran untuk mengetahui karaktersitik konsumen, kepuasan, dan loyalitas konsumen sehingga pihak retoran dapat menjalankan strategi pemasaran Midori Japanese Restaurant cabang K.H. Wahid Hasyim Jakarta Pusat.

Berdasarkan permasalahan di atas, penelitian ini bertujuan untuk :

1. Menganalisis karakteristik dan proses keputusan pembelian konsumen Midori Japanese Restaurant Cabang K.H. Wahid Hasyim.

2. Menganalisis tingkat kepuasan konsumen terhadap Midori Japanese Restaurant Cabang K.H. Wahid Hasyim.

3. Menganalisis tingkat loyalitas konsumen Midori Japanese Restaurant Cabang K.H. Wahid Hasyim.

4. Menentukan strategi pemasaran yang dapat direkomendasikan untuk Midori Japanese Restaurant Cabang K.H. Wahid Hasyim dalam upaya peningkatan kepuasan dan loyalitas konsumen.

\section{KERANGKA PEMIKIRAN}

\section{Kerangka Pemikiran Teoritis}

Engel, et al (1994) serta Kotler dan Armstrong (2008), mendefinisikan perilaku konsumen sebagai suatu sikap yang ditunjukkan oleh konsumen dimulai dai kegiatan sebelum membeli, saat membeli, mengkonsumsi, menghabiskan, dan mengevaluasi kegiatan konsumen yang telah dilakukan. Adapun proses yang dilakukan konsumen dalam pengambilan keputusan meliputi beberapa tahapan. Menurut Engel, et al (1994), 
terdapat lima tahapan keputusan pembelian yang dilakukan oleh konsumen yaitu pengenalan kebutuhan, pencarian informasi, evaluasi alternative, keputusan pembelian, dan perilaku pasca pembelian. Pada tahap perilaku pasca pembelian sangat bermanfaat bagi perusahaan untuk dapat memperbaiki kualitas maupun kuantitas produk atau jasa yang ditawarkan kepada konsumen agar tingkat kepuasan konsumen meningkat.

Sumarwan (2002) mengemukakan bahwa teori yang menjelaskan bagaimana kepuasan atau ketidakpuasan konsumen terbentuk adalah the expectancy disconfirmation model, yang mengemukakan bahwa kepuasan atau ketidakpuasan konsumen merupakan dampak dari perbandingan antara harapan konsumen sebelum pembelian dengan yang sesungguhnya diperoleh konsumen dari produk yang dibeli tersebut.

Pada dasarnya pengertian kepuasan pelanggan mencakup perbedaan antara tingkat kepentingan dan kinerja atau hasil yang dirasakan (Rangkuti, 2002). Pelanggan membentuk ekspektasi tentang nilai dan kepuasan yang diberikan berbagai penawaran pasar dan membeli berdasarkan ekspektasinya itu. Pelanggan yang puas akan membeli lagi dan memberitahu orang lain tentang pengalaman baik mereka. Sedangkan pelanggan yang tidak puas sering berganti ke pesaing dan menjelek-jelekkan produk yang mereka beli kepada orang lain. Nilai dan kepuasan pelanggan merupakan kunci untuk mengembangkan dan menata hubungan pelanggan (Kotler dan Armstrong, 2008).

Konsumen yang merasa puas terhadap produk atau merek yang dikonsumsi atau dipakai akan membeli ulang produk tersebut. Pembelian ulang yang terus menerus dari produk dan merek yang sama akan menunjukkan loyalitas konsumen terhadap merek. Loyalitas merek memiliki beberapa tingkatan. Masing-masing tingkatan mewakili tantangan pemasaran yang berbeda dan mewakili juga tipe asset yang berbeda dalam mengelola dan mengeksploitasinya (Aaker, 1997). Dalam penelitian ini, tingkat loyalitas konsumen terhadap Midori Japanese Restaurant cabang K.H. Wahid Hasyim diukur berdasarkan pertanyaan dalam kuisioner yang telah diberi skor. Penentuan skor dilakukan oleh peneliti dengan tujuan untuk mempermudah peneliti dalam menganalisis tingkat loyalitas konsumen yaitu switcher/price buyer (berpindah-pindah), habitual buyer (pembeli yang bersifat kebiasaan), satisfied buyer (pembeli yang merasa puas dengan biaya peralihan), liking the brand (menyukai merek), dan commited buyer (pembeli yang komitmen). Rangkuti (2009), menyatakan bahwa semua elemen brand loyalty yang telah dihitung dapat dirangkum dalam satu kesatuan yang berbentuk piramida. Tiap tingkatan brand loyalty (rendah atau tinggi) mewakili tantangan pemasar yang berbeda dan mewakili tipe aset yang berbeda.

\section{Kerangka Pemikiran Operasional}

Midori Japanese Restaurant adalah salah satu dari sekian banyak restoran Jepang yang ada di DKI Jakarta. Midori Japanese Restaurant telah memiliki delapan cabang, yaitu enam cabang di DKI Jakarta, satu cabang di Anyer, dan satu cabang di Bandung. Salah satu cabang dari Midori Japanese Restaurant terletak di Jakarta Pusat, tepatnya di Jl. K.H. Wahid Hasyim. Letaknya yang berada di sekitar wilayah perkantoran dan pusat perbenlanjaan membuat Midori Japanese Restaurant cabang ini banyak dikunjungi pelanggan. Rata-rata jumlah pengunjung Midori Japanese Restaurant cabang K.H. Wahid Hasyim setiap bulannya adalah sekitar 1500 orang, yaitu jumlah yang lebih rendah jika dibandingkan dengan cabang lainnya. Dalam menjalankan upaya pengembangan usahanya, pihak restoranmemerlukan pemahaman yang lebih mendalam mengenai konsumennya sehingga dapat mengembangkan strategi pemasaran yang efektif dan efisien dalam menjangkau konsumennya. Pemahaman yang penting dilakukan di antaranya adalah dengan mengetahui karakteristik konsumen, proses 
pengambilan keputusan pembelian konsumen, tingkat kepuasan konsumen, dan tingkat loyalitas konsumen.

Atribut-atribut yang digunakan dalam pengukuran tingkat kepuasan konsumen restoran ini mencakup atribut produk dan pelayanan yang merupakan penjabaran dari 7P bauran pemasaran (marketing mix), yaitu product (produk), price (harga), place (tempat), promotion (promosi), people (orang), process (proses), dan physical evidence (bukti fisik). Penentuan atribut-atribut tersebut diperoleh melalui diskusi antara peneliti dengan pihak restoran dan juga diperoleh berdasarkan penelitian terdahulu. Terdapat 22 atribut sebagai berikut :atribut produk (cita rasa makanan dan minuman, porsi makanan dan minuman, aroma makanan dan minuman, kesegaran bahan makanan dan minuman, tampilan penyajian makanan dan minuman), atribut harga (harga makanan dan minuman), atribut orang (kesigapan pelayan, keramahan dan kesopanan pelayan, penampilan pelayan), atribut proses (kecepatan transaksi/pembayaran), atribut tempat (ketersediaan area parkir, kemudahan akses ke lokasi restoran, kebersihan ruangan restoran, kenyamanan restoran), atribut promosi (papan nama restoran, promosi restoran, reward/hadiah yang diberikan oleh restoran), serta atribut bukti fisik (kebersihan toilet dan wastafel, penataan eksterior dan interior restoran, kebersihan peralatan makan, ketersediaan fasilitas customer service).

\section{METODOLOGI}

Penelitian ini dilaksanakan di Midori Japanese Restaurant yaitu yang berlokasi di Jl. K.H. Wahid Hasyim No. 106, Jakarta Pusat. Pengambilan data dilakukan pada bulan Maret hingga bulan Mei 2010. Data meliputi data primer yang diperoleh melalui wawancara kepada responden melalui pengisian kuisioner serta data sekunder yang diperoleh dari Dinas Pariwisata dan Kebudayaan Provinsi DKI Jakarta, Badan Pusat Statistik (BPS) Pusat di Jakarta, instansi yang terkait lainnya, perpustakaan, jurnal, buku, skripsi terdahulu, dan internet.

Metode penentuan sampel yang digunakan adalah metode Non Probability Sampling dengan jenisnya yaitu convenience sampling. Sedangkan metode pengumpulan data yang digunakan pada penelitian ini adalah metode survei. Penyebaran kuisioner dilakukan pada hari kerja (Senin-Jumat) dan kemungkinan hari libur (Sabtu, Minggu, dan hari libur nasional) di sepanjang jam kerja restoran (10.0022.00 WIB), terutama pada saat jam makan. Jumlah responden yang diambil untuk dijadikan sampel dalam penelitian ini adalah sebanyak 60 responden yang dilakukan secara bebas namun telah lolos tahap screening terlebih dahulu yaitu responden yang sudah pernah melakukan pembelian di Midori Japanese Restaurant cabang K.H. Wahid Hasyim.

Untuk mengetahui karakteristik konsumen dan proses keputusan pembelian digunakan Analisis Deskriptif. Analisis lain yang digunakan adalah Importance Performance Analysis (IPA) dan Customer Satisfaction Index (CSI) untuk mengukur tingkat kepuasan konsumen. Pengukuran tingkat loyalitas konsumen menggunakan piramida loyalitas konsumen. Data diolah dengan menggunakan software Microsoft Excel 2007 untuk tabulasi data dan perhitungan Customer Satisfaction Index (CSI), SPSS 11,5 untuk perhitungan Importance Performance Analysis (IPA), serta Minitab 14 untuk pembuatan matriks plot dari Importance Performance Analysis (IPA).

Atribut-atribut dalam kuisioner terlebih dahulu dilakukan pengujian dengan uji validitas dan uji reliabilitas yang dilakukan terhadap 30 responden (di luar 60 responden yang dibutuhkan dalam penelitian). Menilai valid/tidaknya masing-masing variabel (atribut) dapat dilihat dari nilai corrected item-total correlation masing-masing variabel 
(atribut). Suatu variabel (atribut) dapat dikatakan valid jika nilai corrected item-total correlation > 0.3 dan dikatakan tidak valid jika nilai corrected item-total correlation $<0.3$ (Nugroho, 2005). Variabel (atribut) yang tidak valid harus dihilangkan dan tidak ditanyakan kepada responden pada saat pengambilan data dalam penelitian. Hasil uji validitas menunjukkan semua atribut memiliki nilai corrected item-total correlation $>0.3$, yaitu berkisar antara 0.3176-0.8248. Dengan demikian dapat dikatakan bahwa semua atribut tersebut valid dapat dijadikan alat ukur dalam penelitian ini.

Reliabilitas merupakan ukuran suatu kestabilan dan konsistensi responden dalam menjawab hal yang berkaitan dengan konstruk-konstruk pertanyaan yang nerupakan dimensi suatu variabel dan disusun dalam suatu bentuk kuesioner (Nugroho, 2005). Teknik pengukuran reliabilitas yang digunakan adalah teknik Cronbach karena skala yang digunakan dalam penelitian ini adalah skala Likert (1-5). Uji reliabilitas juga dilakukan dengan menggunakan software SPSS 11,5. Hasil uji reliabilitas mennunjukkan bahwa semua atribut dikatakan sangat reliabel karena memiliki nilai Alpha $=0,9294$ (dalam rentang $0,81-1,00$ ). Dengan demikian semua atribut sudah konsisten dalam pengukurannya.

\section{HASIL DAN PEMBAHASAN}

\section{Karakteristik Umum Konsumen}

Karakteristik umum konsumen yang terdapat dalam penelitian ini meliputi jenis kelamin, usia, kebangsaan, status, pendidikan, pekerjaan, dan pengeluaran rata-rata per bulan (Tabel 2). Berdasarkan jenis kelamin, jumlah responden perempuan lebih banyak dibandingkan dengan laki-laki yaitu sebesar 61,7 persen sedangkan sisanya adalah persentase jumlah laki-laki. Jumlah perempuan yang lebih banyak daripada laki-laki dikarenakan konsumen yang datang ke Midori Japanese Restaurant Cabang K.H. Wahid Hasyim Jakarta Pusat merupakan konsumen yang juga mengunjungi Bersih Sehat di mana mayoritas konsumennya adalah perempuan yang melakukan pijat kesehatan.

Sebagian besar usia responden adalah usia dewasa lanjut (24-30 tahun dan 31-40 tahun) sebanyak total 36 orang. Hal ini dikarenakan usia tersebut merupakan usia produktif seseorang dan memiliki pendapatan yang cukup untuk melakukan pembelian. Berdasarkan kebangsaan, 98,3 persen (59 orang) konsumen berkebangsaan WNI (Warga Negara Indonesia). Sedangkan hanya terdapat 1,7 persen (1 orang) konsumen yang berkebangsaan WNA (Warga Negara Asing) yaitu berasal dari Jepang.

Sebagian besar responden sudah menikah yaitu sebanyak 60 persen (36 orang) dan sisanya belum menikah. Midori Japanese Restaurant Cabang K.H. Wahid Hasyim Jakarta Pusat ditujukan bagi seluruh konsumen tanpa melihat status pernikahan konsumennya.

Tingkat pendidikan responden dalam penelitian ini dapat dikatakan tinggi. Hal ini dapat terlihat dari banyaknya responden yang merupakan lulusan perguruan tinggi. Sebanyak $11,7 \%$ konsumen memiliki gelar Diploma, 65\% konsumen memiliki gelar Sarjana, 21,7\% persen memiliki gelar Pascasarjana, dan hanya 1,7\% yang lulusan SMA. Semakin tinggi tingkat pendidikan seseorang, akan semakin tinggi pula wawasan yang dimiliki. Orang tersebut akan lebih mudah mencari, menerima, dan mencerna informasiinformasi yang ada. 
Tabel 2. Karakteristik Umum Konsumen Midori Japanese Restaurant Cabang K.H. Wahid Hasyim Jakarta Pusat

\begin{tabular}{|c|c|c|}
\hline Karakteristik Umum Konsumen & Jumlah & Persentase (\%) \\
\hline \multicolumn{3}{|l|}{ Jenis Kelamin } \\
\hline - Laki-laki & 23 & 38,3 \\
\hline - Perempuan & 37 & 61,7 \\
\hline \multicolumn{3}{|l|}{ Usia } \\
\hline - $\quad$ 17-23 tahun & 3 & 5,0 \\
\hline - 24-30 tahun & 18 & 30,0 \\
\hline - 31-40 tahun & 18 & 30,0 \\
\hline - 41-50 tahun & 7 & 11,7 \\
\hline - 51-65 tahun & 11 & 18,7 \\
\hline - $\quad>65$ tahun & 3 & 5,0 \\
\hline \multicolumn{3}{|l|}{ Kebangsaan } \\
\hline - WNI & 59 & 98,3 \\
\hline - WNA & 1 & 1,7 \\
\hline \multicolumn{3}{|l|}{ Status Pernikahan } \\
\hline - Belum menikah & 24 & 40,0 \\
\hline - Menikah & 36 & 60,0 \\
\hline \multicolumn{3}{|l|}{ Pendidikan } \\
\hline - SD & 0 & 0,0 \\
\hline - SMP & 0 & 0,0 \\
\hline - SMA & 1 & 1,7 \\
\hline - Diploma & 7 & 11,7 \\
\hline - Sarjana & 39 & 65,0 \\
\hline - Pascasarjana & 13 & 21,7 \\
\hline \multicolumn{3}{|l|}{ Pekerjaan } \\
\hline - Pelajar/mahasiswa & 2 & 3,3 \\
\hline - Pegawai/karyawan swasta & 31 & 51,7 \\
\hline - $\quad$ PNS & 1 & 1,7 \\
\hline - Wiraswasta & 4 & 6,7 \\
\hline - Pensiunan & 1 & 1,7 \\
\hline - Ibu rumah tangga & 2 & 3,3 \\
\hline - Lainnya & 19 & 31,7 \\
\hline \multicolumn{3}{|l|}{ Pengeluaran rata-rata per bulan } \\
\hline - $\quad<\operatorname{Rp} 500.000$ & 0 & 0,0 \\
\hline - $\quad \operatorname{Rp} 500.000$ - Rp 1.000 .000 & 6 & 10,0 \\
\hline - $\quad \operatorname{Rp} 1.000 .001-\operatorname{Rp} 3.000 .000$ & 14 & 23,3 \\
\hline - $\quad \operatorname{Rp} 3.000 .001-\operatorname{Rp} 5.000 .000$ & 13 & 21,7 \\
\hline - $\quad>\operatorname{Rp} 5.000 .000$ & 27 & 45,0 \\
\hline
\end{tabular}

Sebagian besar konsumen dalam penelitian ini berprofesi sebagai pegawai/karyawan swasta yaitu sebanyak $51,7 \%$. Berdasarkan hasil tersebut, wajar jika sebagian besar konsumen memiliki pekerjaan sebagai pegawai/karyawan karena lokasi restoran yang dekat dengan pusat perkantoran. Pengeluaran rata-rata per bulan, konsumen sebagian besar (45\%) > Rp. 5.000.000. Hal ini menunjukkan bahwa restoran ini memang ditujukan untuk konsumen kalangan menengah ke atas.

\section{Proses Keputusan Pembelian Konsumen}

Berdasarkan hasil penelitian untuk proses keputusan pembelian pada tahap pengenalan kebutuhan, konsumen restoran ini secara keseluruhan merupakan konsumen yang memiliki motivasi melakukan pembelian di restoran karena adanya variasi makanan dan mencari manfaat mudah/tidak repot saat melakukan pembelian di 
restoran. Untuk tahap pencarian informasi, secara keseluruhan konsumen memperoleh informasi mengenai restoran dari teman dan rasa adalah fokus utama konsumen dari sumber informasi tersebut. Konsumen juga menganggap bahwa rasa yang enak adalah salah satu hal yang perlu dibandingkan dalam pemilihan restoran. Kenyamanan suasana restoran adalah hal yang dipertimbangkan oleh sebagian besar konsumen dalam memilih restoran yang menawarkan menu masakan Jepang dan juga mempertimbangkan cita rasa makanan dan minuman dalam memilih restoran Jepang pilihan konsumen.

Untuk tahap keputusan pembelian, konsumen restoran ini melakukan pembelian secara terencana dan melakukan pembelian bersama teman dan keluarga. Secara keseluruhan, konsumen merasakan kepuasan setelah mengkonsumsi produk restoran ini, sehingga ingin melakukan pembelian kembali, dan konsumen telah merekomendasikan restoran ini kepada orang lain agar melakukan pembelian di restoran ini.

\section{Analisis Kepuasan Konsumen}

Berdasarkan hasil analisis, nilai Customer Satisfaction Index (CSI) pada Midori Japanese Restaurant Cabang K.H. Wahid Hasyim Jakarta Pusat sebesar 74,28 persen. Nilai ini diperoleh dengan cara membagi nilai Weighted Average dengan skala maksimum pada skala Likert yang digunakan dalam penelitian ini, yaitu skala maksimum 5 (lima) kemudian dikalikan dengan 100 persen. Berdasarkan indeks kepuasan, nilai Customer Satisfaction Index (CSI) sebesar 74,28 persen berada pada rentang skala 0,66-0,80, yang dapat dikatakan bahwa secara umum indeks kepuasan konsumen Midori Japanese Restaurant Cabang K.H. Wahid Hasyim termasuk ke dalam kategori "puas" (Tabel 3).

Namun demikian, Midori Japanese Restaurant Cabang K.H. Wahid Hasyim Jakarta Pusat tetap harus meningkatkan kinerjanya karena masih tersisa sebanyak 25,72 persen nilai kepuasan atribut yang dapat dikatakan termasuk dalam kategori tidak puas. Sehingga pihak restoran perlu mengetahui dan menilai lebih lanjut kepuasan konsumen terhadap atribut-atribut dilihat dari tingkat kepentingan (importance) dan tingkat kinerja (performance) atribut.

Berdasarkan hasil perhitungan Importance Performance Analysis (IPA), atributatribut yang termasuk dalam kuadran I (kinerja perlu diperbaiki) adalah harga makanan dan minuman serta ketersediaan area parkir; kuadran II (kinerja tetap dipertahankan) adalah cita rasa makanan dan minuman, kehigienisan dan kesegaran bahan makanan dan minuman, kesigapan pelayan, keramahan dan kesopanan pelayan, ketersediaan dan kebersihan toilet serta wastafel, kebersihan peralatan makan, kebersihan dan kerapihan ruangan restoran, serta keamanan dan kenyamanan restoran; kuadran III (bukan prioritas utama dalam perbaikan kinerja) adalah aroma makanan dan minuman, kecepatan transaksi/pembayaran, papan nama restoran, promosi restoran, ketersediaan fasilitas customer service, dan reward/hadiah yang diberikan oleh restoran; dan kuadran IV (kinerja perlu dikurangi) adalah porsi makanan dan minuman, tampilan penyajian makanan dan minuman, keragaman menu, penampilan pelayan (seragam pelayan), kemudahan akses ke lokasi restoran, dan penataan eksterior dan interior restoran (Gambar 1) 
Tabel 3. Perhitungan Customer Satisfaction Index (CSI) Midori Japanese Restaurant Cabang K.H. Wahid Hasyim Jakarta Pusat

\begin{tabular}{rrrrr}
\hline Atribut & $\begin{array}{r}\text { Rata- } \\
\text { Rata Skor } \\
\text { Kepentingan }\end{array}$ & $\begin{array}{c}\text { Importance } \\
\text { Weighting } \\
\text { Factor (\%) }\end{array}$ & $\begin{array}{c}\text { Rata-Rata } \\
\text { Skor Kinerja }\end{array}$ & \multicolumn{2}{c}{$\begin{array}{l}\text { Weighted } \\
\text { Score }\end{array}$} \\
\hline 1 & 4,58 & 5,04 & 3,98 & 0,20 \\
2 & 3,87 & 4,25 & 3,78 & 0,16 \\
3 & 4,03 & 4,43 & 3,63 & 0,16 \\
4 & 4,68 & 5,15 & 4,00 & 0,21 \\
5 & 4,13 & 4,54 & 3,90 & 0,18 \\
6 & 3,93 & 4,32 & 3,82 & 0,17 \\
7 & 4,20 & 4,61 & 3,53 & 0,16 \\
8 & 4,47 & 4,91 & 3,87 & 0,19 \\
9 & 4,42 & 4,85 & 3,87 & 0,19 \\
10 & 4,00 & 4,40 & 3,75 & 0,16 \\
11 & 4,02 & 4,41 & 3,47 & 0,15 \\
12 & 4,18 & 4,60 & 3,27 & 0,15 \\
13 & 4,47 & 4,91 & 4,02 & 0,20 \\
14 & 4,63 & 5,09 & 3,88 & 0,20 \\
15 & 3,67 & 4,03 & 3,20 & 0,13 \\
16 & 3,80 & 4,18 & 3,22 & 0,13 \\
17 & 4,05 & 4,45 & 3,72 & 0,17 \\
18 & 3,97 & 4,36 & 3,92 & 0,17 \\
19 & 4,40 & 4,84 & 4,00 & 0,19 \\
20 & 4,38 & 4,82 & 3,92 & 0,19 \\
21 & 3,70 & 4,07 & 3,42 & 0,14 \\
22 & 3,40 & 3,74 & 3,18 & 0,12 \\
\hline Total & $\mathbf{9 0 , 9 8}$ & $\mathbf{1 0 0 , 0 0}$ & $\mathbf{8 1 , 3 3}$ & \\
\hline Weighted & & & & $\mathbf{3 , 7 1}$ \\
\hline Average & & & & $\mathbf{7 4 , 2 8}$ \\
\hline Customer Satisfaction Index(\%) & & & \\
\hline
\end{tabular}

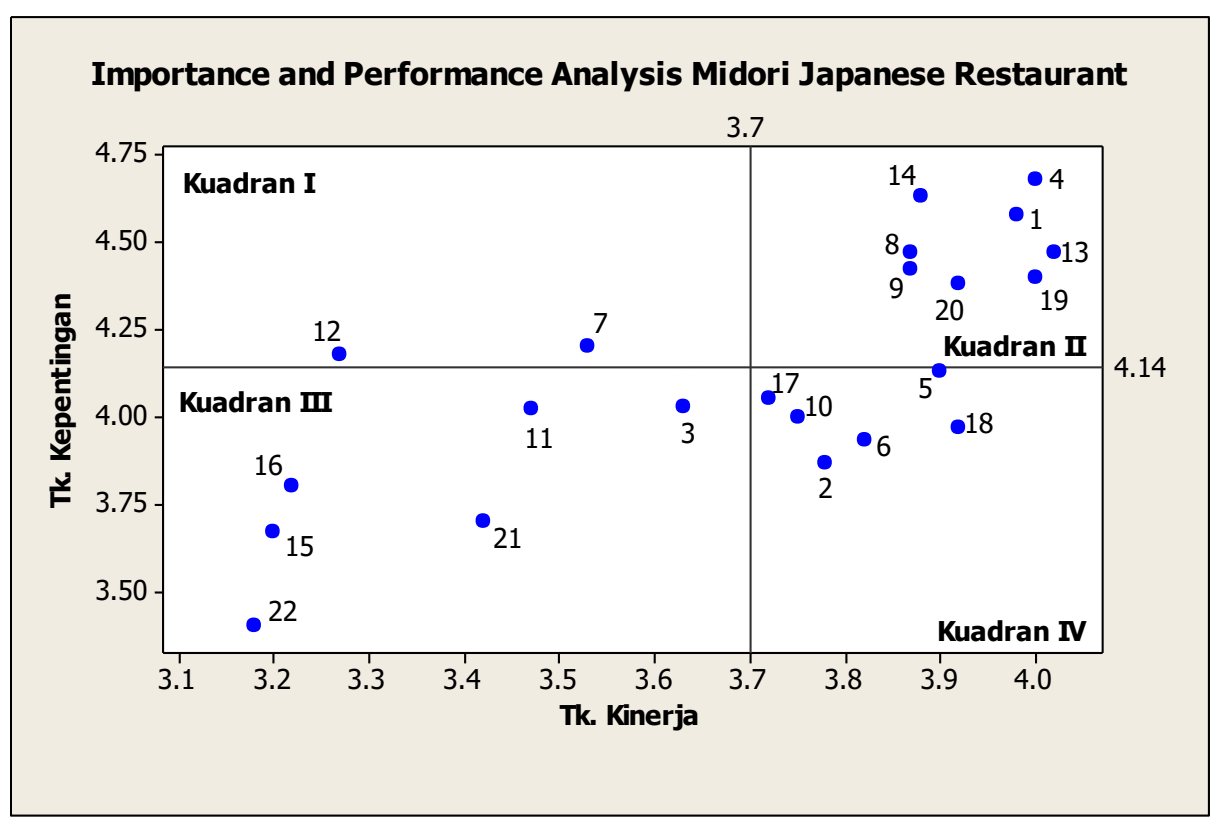

Gambar 1. Diagram Kartesius Importance Performance Analysis (IPA) Midori Japanese Restaurant Cabang K.H. Wahid Hasyim Jakarta Pusat 


\section{Analisis Loyalitas Konsumen}

Berdasarkan hasil penelitian diketahui bahwa terdapat sebanyak 3.3\% konsumen tipe switcher buyer, $8.3 \%$ konsumen tipe habitual buyer, $1.7 \%$ konsumen tipe satisfied buyer, 30\% konsumen tipe liking the brand, dan sebanyak 56.7\% konsumen dengan tipe commited buyer. Dengan kata lain, sebagian besar konsumen restoran ini termasuk ke dalam konsumen yang loyal. Namun, pihak restoran harus tetap meningkatkan kepuasan dan loyalitas konsumen agar jumlah konsumen dengan tipe liking the brand dan commited buyer semakin meningkat.

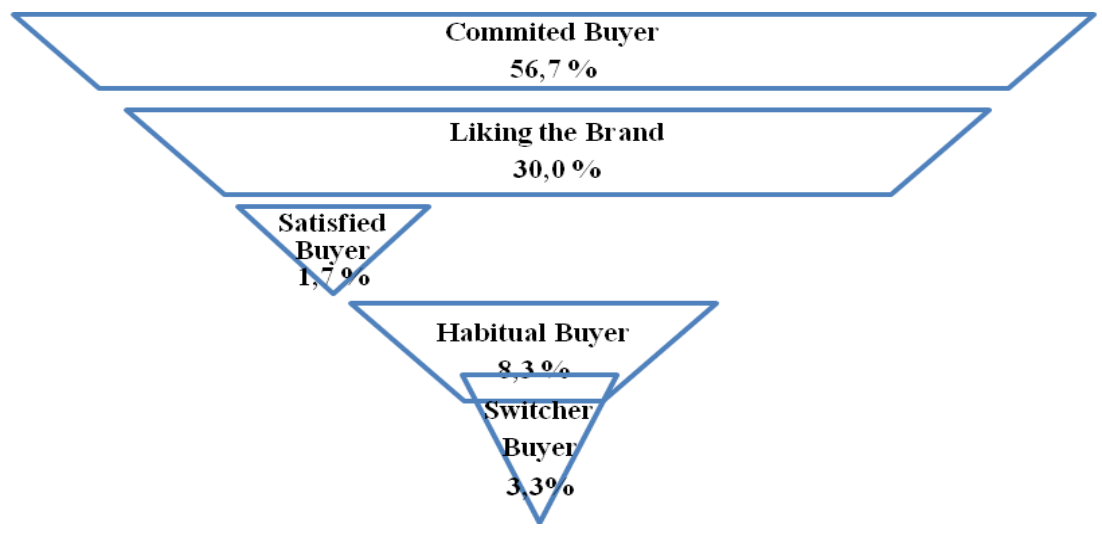

Gambar 2. Piramida Loyalitas Konsumen Midori Japanese Restaurant Cabang K.H.

Wahid Hasyim Jakarta Pusat

\section{Implikasi Strategi Bauran Pemasaran}

Hasil dari analisis kepuasan dan loyalitas konsumen berimplikasi terhadap strategi bauran pemasaran. Strategi pemasaran Midori Japanese Restaurant Cabang K.H. Wahid Hasyim Jakarta Pusat berkaitan dengan tujuh bauran pemasaran (7P), yaitu strategi produk (product), harga (price), tempat (place), promosi (promotion), orang (people), proses (process), dan bukti fisik (physical evidence).

\section{Strategi Produk (Product)}

Atribut cita rasa makanan dan minuman yang disajikan oleh Midori Japanese Restaurant Cabang K.H. Wahid Hasyim Jakarta Pusat merupakan atribut yang dianggap sangat penting oleh konsumen. Konsumen menilai kinerja dari atribut cita rasa makanan dan minuman sudah baik dan hal ini terlihat dari kepuasan yang dirasakan sebagian besar konsumen. Kinerja yang baik ini harus terus dipertahankan oleh pihak restoran. begitu pula dengan tampilan penyajian makanan dan menu yang dirasa sudah menarik sehingga perlu dipertahankan oleh pihak restoran.

\section{Strategi Harga (Price)}

Masih ada beberapa konsumen yang merasa tidak puas dengan harga makanan dan minuman yang ditawarkan oleh restoran ini. Konsumen merasa harga yang ditawarkan cenderung semakin meningkat. Selain itu berdasarkan piramida loyalitas konsumen, masih terdapat konsumen yang tergolong ke dalam konsumen tipe switcher buyer, yaitu konsumen yang sangat dipengaruhi oleh faktor harga. Oleh karena itu, sebaiknya restoran ini tetap mempertahankan kualitas produk dan pelayanan restoran dengan harga tetap dan tidak cenderung untuk terus meningkat. Hal ini dilakukan agar konsumen merasa semakin puas dan semakin loyal dengan restoran ini. Jika pihak restoran tetap ingin menaikkan harga, sebaiknya kenaikan ini juga diimbangi dengan semakin baiknya kualitas produk dan pelayanan restoran. 


\section{Strategi Tempat (Place)}

Dalam penelitian ini, diketahui bahwa konsumen masih merasakan ketidakpuasan terhadap area parkir yang tersedia di restoran ini sehingga kinerja atribut ini perlu untuk ditingkatkan. Salah satu strategi yang dapat dilakukan oleh pihak restoran adalah bekerjasama dengan gedung perkantoran yang terletak di sebelah restoran di mana area parkir perkantoran dapat digunakan oleh restoran untuk area parkir konsumen di saat jam kerja perkantoran telah habis. Hal ini dilakukan agar tidak terjadi penumpukan kendaraan konsumen dan mengantisipasi keluhan yang mungkin akan datang dari konsumen.

\section{Strategi Promosi (Promotion)}

Berdasarkan hasil penelitian, masih ada beberapa konsumen yang belum merasa puas terhadap promosi yang dilakukan oleh pihak restoran. Salah satu strategi yang dapat dilakukan oleh pihak restoran adalah bekerjasama dengan bank dalam memberikan diskon/potongan harga untuk produk-produk tertentu sehingga akan lebih menarik minat konsumen dalam membeli produk restoran, dengan ketentuan dan syarat berlaku jika menggunakan kartu kredit bank tersebut. Selama ini pihak restoran belum pernah bekerjasama dengan bank untuk mempromosikan produk-produknya.

Selain itu, pihak Midori Japanese Restaurant juga dapat memberikan penawaran membership kepada konsumen agar konsumen semakin loyal terhadap restoran. Penawaran membership ini dirasa akan sangat menguntungkan bagi konsumen yang termasuk dalam konsumen dengan tipe commited buyer. Strategi lain yang juga dapat dilakukan adalah strategi yang sebelumnya telah dilakukan oleh Warung Ngalam, yaitu dengan pengisian kupon undian di mana setiap bulannya akan diundi 10 pemenang dan berhak mendapatkan hadiah berupa voucher makan bernilai $\mathrm{Rp} 50.000$,-/voucher.

\section{Strategi Orang (People)}

Sejauh ini, kesigapan pelayan serta keramahan dan kesopanan pelayan dianggap penting dan memiliki kinerja yang sudah dirasa baik oleh konsumen. Oleh karena itu, pihak restoran perlu untuk mempertahankan kinerja pelayan tersebut. Salah satu hal yang dapat disarankan memberikan tambahan softskill kepada karyawannya dalam hal bahasa asing seperti bahasa Inggris dan Jepang. Hal ini bertujuan agar pelayan dapat dengan mudah melakukan komunikasi dengan konsumen asing.

\section{Strategi Proses (Process)}

Pihak restoran perlu memperhatikan proses yang ada dalam setiap kegiatan usaha seperti proses transaksi/pembayaran. Atribut kecepatan transaksi/pembayaran perlu diperhatikan oleh pihak restoran terutama di saat jam makan siang. Hal ini dikarenakan sebagian besar konsumen karyawan/pegawai kantor yang tidak memiliki waktu banyak untuk istirahat siang. Strategi yang saat ini sudah mulai dijalankan oleh pihak restoran yaitu menawarkan menu paket makan siang dengan proses penyajian yang hanya membutuhkan waktu selama lima menit. Strategi ini perlu dipertahankan oleh pihak restoran untuk semakin meningkatkan kepuasan konsumen yang sebagian besar terdiri dari karyawan/pegawai kantor.

\section{Strategi Bukti Fisik (Physical Evidence)}

Sebagian besar fasilitas penunjang yang tersedia sudah dirasa baik oleh konsumen sehingga kinerjanya perlu dipertahankan. Namun ada satu fasilitas penunjang yang manfaatnya belum begitu dirasakan oleh konsumen, yaitu fasilitas customer service. Hal ini dikarenakan sebagian besar konsumen menyampaikan keluhannya secara langsung kepada pelayan atau supervisor yang ada di saat konsumen melakukan pembelian. Pihak restoran dapat memanfaatkan fasilitas customer service ini tidak hanya untuk menampung keluhan konsumen tetapi juga sebagai contact person apabila konsumen ingin melakukan pemesanan khusus kepada pihak restoran seperti penyewaan ruangan restoran untuk acara-acara tertentu. 


\section{SIMPULAN DAN SARAN}

\section{Simpulan}

1. Karakteristik konsumen Midori Japanese Restaurant Cabang K.H. Wahid Hasyim Jakarta Pusat, sebagian besar usia responden adalah usia dewasa lanjut, berjenis kelamin perempuan, berkebangsaan Indonesia, sudah menikah, berpendidikan terakhir sarjana, berprofesi sebagai pegawai/karyawan swasta, dan memiliki pengeluaran rata-rata per bulan $>\mathrm{Rp} 5.000 .000$.

2. Atribut kinerjanya perlu diperbaiki adalah harga makanan dan minuman serta ketersediaan area parkir. Sedangkan atribut yang kinerjanya perlu dipertahankan adalah cita rasa makanan dan minuman, kehigienisan dan kesegaran bahan makanan dan minuman, kesigapan pelayan, keramahan dan kesopanan pelayan, ketersediaan dan kebersihan toilet serta wastafel, kebersihan peralatan makan, kebersihan dan kerapihan ruangan restoran, serta keamanan dan kenyamanan restoran. Atribut yang tidak menjadi prioritas utama dalam perbaikan kinerja adalah aroma makanan dan minuman, kecepatan transaksi/pembayaran, papan nama restoran, promosi restoran, ketersediaan fasilitas customer service, dan reward/hadiah yang diberikan oleh restoran. Atribut yang perlu dikurangi kinerjanya adalah porsi makanan dan minuman, tampilan penyajian makanan dan minuman, keragaman menu, penampilan pelayan (seragam pelayan), kemudahan akses ke lokasi restoran, dan penataan eksterior dan interior restoran.

3. Midori Japanese Restaurant Cabang K.H. Wahid Hasyim Jakarta Pusat memiliki konsumen yang sebagian besar termasuk ke dalam tipe commited buyer, yaitu konsumen yang loyal/setia terhadap suatu merek.

4. Dalam rangka meningkatkan kepuasan dan loyalitas konsumen, rekomendasi strategi bauran yang menjadi prioritas adalah tetap mempertahankan kualitas produk dan pelayanan restoran dengan harga tetap dan tidak cenderung meningkat. Bekerjasama dengan gedung perkantoran yang terletak di sebelah restoran di mana area parkir perkantoran dapat digunakan oleh restoran untuk area parkir konsumen di saat jam kerja perkantoran telah habis.

\section{Saran}

1. Perlu memperbaiki atribut-atribut yang dirasa masih memiliki kinerja yang kurang baik bagi konsumen dan mempertahankan atribut-atribut restoran dengan kinerja yang baik. Hal ini ditujukan agar konsumen semakin puas terhadap atribut-atribut tersebut.

2. Sebaiknya mempertahankan kualitas produk dan pelayan yang selama ini telah ditawarkan kepada konsumen. Tetapi pihak restoran juga perlu untuk meningkatkan kualitas tersebut agar tidak ada lagi konsumen dari Midori Japanese Restaurant Cabang K.H. Wahid Hasyim Jakarta Pusat yang termasuk dalam tipe switcher buyer.

3. Terus melakukan strategi bauran pemasaran agar dapat tetap bersaing dengan restoran lain yang sejenis.

\section{DAFTAR PUSTAKA}

AakerDA. 1997. Manajemen Ekuitas Merek. Ananda A, penerjemah; Jakarta: Mitra Utama. Terjemahan dari: Managing Brand Equity: Capitalizing on the Value of a Brand Name. 
Dinas Pariwisata dan Kebudayaan Provinsi DKI Jakarta. 2010. Data Pariwisata dan Kebudayaan Provinsi DKI Jakarta. Jakarta: Dinas Pariwisata dan Kebudayaan Provinsi DKI Jakarta.

Engel JF, et al. 1994. Perilaku Konsumen. Ed ke-6 Jilid 1. Budiyanto, penerjemah; Jakarta: Binarupa Aksara. Terjemahan dari: Consumer Behaviour. $6^{\text {th }}$ Ed Jilid 1.

Engel JF, et al. 1994. Perilaku Konsumen. Ed ke-6 Jilid 2. Budijanto, penerjemah; Jakarta: Binarupa Aksara. Terjemahan dari: Consumer Behaviour. $6^{\text {th }}$ Ed Jilid 2.

Nazir M. 1983. Metode Penelitian. Jakarta: Ghalia Indonesia.

Nugroho BA. 2005. Strategi Jitu Memilih Metode Statistik Penelitian dengan SPSS. Yogyakarta: Penerbit Andi.

Rangkuti F. 2002. Measuring Customer Satisfaction: Teknik Mengukur dan Strategi Meningkatkan Kepuasan Pelanggan. Jakarta: PT Gramedia Pustaka Utama.

Sumarwan U. 2002. Perilaku Konsumen: Teori dan Penerapannya dalam Pemasaran. Bogor: Penerbit Ghalia Indonesia.

Umar H. 2002. Metode Riset Bisnis. Jaka5rta: PT Gramedia Pustaka Utama. 